\title{
A (RE)CONSTRUÇÃO DA IDEIA DE DIGNIDADE HUMANA
}

\author{
Vicente de Paulo Barretto ${ }^{1}$ \\ Elis Cristina Uhry Lauxen ${ }^{2}$
}

\section{Resumo}

A dignidade humana é considerada base e referência na ordem jurídica contemporânea. Em que pese a sua relevância e a positivação nas declarações internacionais e em significativo número de sistemas constitucionais, a carência de compreensão da ideia de dignidade e as transformações dos valores da sociedade, podem causar o uso reducionista ou até mesmo indiscriminado do princípio da dignidade humana, esvaziando seu próprio sentido no sistema jurídico. Assim, o presente artigo tem como objetivo investigar a noção de dignidade humana, considerando as mudanças da sociedade, principalmente aquelas promovidas nas últimas décadas, pelo progresso da ciência e da tecnologia. Para desenvolver a pesquisa, utilizou-se como método de abordagem a ética hermenêutica crítica, na qual a ética é o centro do processo de compreensão e interpretação, observando-se os contornos da faticidade. Como resultado, constatou-se que para a efetividade da dignidade humana como um referencial hermenêutico, mormente no contexto das velozes e abrangentes mutações promovidas pelos avanços tecnocientíficos, é imprescindível refletir e compreender o contínuo processo de (re)construção da ideia de dignidade humana, com base em um conjunto de valores, que abrange os fundamentos filosóficos, jurídicos, éticos e multiculturais das sociedades.

Palavras-chave: Dignidade humana. Transformações sociais. Desenvolvimento tecnocientífico. Ética. Direito.

\section{INTRODUÇÃO}

A dignidade humana passou a ser considerada, nas últimas décadas, um valor central do ordenamento jurídico em âmbito nacional e supranacional. Todavia, não obstante a relevância da dignidade e sua positivação nos sistemas jurídicos, há dificuldades de compreensão do seu próprio conteúdo. A carência de compreensão do significado de dignidade humana, acompanhado das velozes e abrangentes mudanças promovidas pelo desenvolvimento tecnocientífico, podem provocar a aplicação reducionista ou generalizada da ideia de dignidade humana, em detrimento de sua efetividade.

Diante deste contexto, o presente artigo tem como objetivo perquirir acerca da evolução e compreensão

\footnotetext{
${ }^{1}$ Livre-docente/Doutor pela PUC-RIO. Professor dos Programas de Pós-Graduação da UNESA e da UNISINOS. E-mail: vpbarreto@terra.com.br

${ }^{2}$ Mestre em Direito pela Universidade do Vale do Rio dos Sinos - UNISINOS. Professora da Universidade de Santa Cruz do Sul UNISC. Pesquisadora do Laboratório de Pesquisa em Bioética e Ética na Ciência do Hospital de Clínicas de Porto Alegre LAPEBEC/HCPA. E-mail: eclauxen@gmail.com
} 
da noção de dignidade humana que perpassam as transformações da sociedade, principalmente no contexto da evolução da ciência e da tecnologia. Para desenvolver o objetivo proposto, será utilizado como método de abordagem a ética hermenêutica crítica, indicada por Conill Sancho (2010) como uma possibilidade para fazer frente ao progresso científico, considerando a ética como o centro do processo que envolve a compreensão e interpretação, observando os contornos da facticidade. Assim, buscar-se-á refletir acerca da importância da compreensão da ideia de dignidade humana, para a sua efetividade como referencial hermenêutico na busca do sentido das normas existentes e no processo de construção de parâmetros éticos e jurídicos para nortear as novas situações advindas das mudanças que ocorrem na sociedade.

\section{ORIGEM E EVOLUÇÃO DA NOÇÃO DE DIGNIDADE}

O entendimento no sentido de que o ser humano é dotado de dignidade existe desde a antiguidade. Todavia, no decorrer da história, foram agregados valores à compreensão de pessoa humana, que consequentemente levaram à evolução da concepção de dignidade humana (BARRETTO, 2013, p. 63-64).

$\mathrm{Na}$ Antiguidade clássica, a ideia de dignidade humana estava relacionada, em regra, à posição que o indivíduo ocupava na sociedade ou o seu grau de reconhecimento pelos demais membros da comunidade. Nessa linha de raciocínio, existia uma espécie de quantificação ou modulação da dignidade, de modo que as pessoas eram consideradas mais ou menos dignas, de acordo com os parâmetros acima referidos (SARLET, 2009. p. 212213).

Todavia, mesmo nos estágios iniciais, a noção de dignidade foi além da atribuição de um status elevado aos indivíduos em uma sociedade. Para o estóicos ${ }^{3}$, todos os seres humanos eram considerados iguais em dignidade, qualidade que os distinguia em relação às demais criaturas. Nessa perspectiva, principalmente a partir de Cícero, em Roma, a dignidade passou a ter um sentido mais amplo, com base na natureza humana, de modo que o que estava em questão não era a posição que um indivíduo ou um grupo ocupavam em relação aos outros seres humanos em determinada sociedade, mas a posição superior dos seres humanos no Universo (ROSEN, 2012.p. 10-11).

$\mathrm{Na}$ Idade Média, a dignidade humana encontrou fundamento, principalmente, no pensamento tomasiano, que partiu da noção de Boécio (1979, p. 557) no sentido de que a "pessoa é substância individual da natureza racional". Nessa perspectiva, Tomás de Aquino (2003, p. 522) defendia que em razão da racionalidade, o indivíduo detinha o domínio de seus atos, de modo que poderia agir por si mesmo e, entre as outras "substâncias",

\footnotetext{
${ }^{3}$ Estoicismo. Origem na palavra grega stoa, que significa pórtico, como referência ao local onde Zenão de Cicio (334-262 a.C. aproximadamente) se reunia com seus discípulos em Atenas, em torno do ano 300 a.C., para travar discussões filosóficas. A escola a partir daí formada recebe a denominação de estóica ou estoicismo. Trata-se de uma tendência filosófica presente nas culturas grega e romana da Antiguidade. (MENDONÇA, 2009. p. 295).
} 
isto é, entre os outros seres, chamava-se pessoa. Ademais, na compreensão de Santo Tomás (2002, p 355) o ser humano era composto de substância espiritual e corporal, tendo como essência a alma, como bem asseverava: "a alma é o motor do corpo". Assim, a pessoa era considerada a realização mais plena, que ocupava o grau mais alto na escala dos seres, razão pela qual os seres que ostentavam o título de pessoa detinham uma dignidade infinita e um valor absoluto (JUNGES, 2006, p. 107).

Por intermédio do cristianismo, foram introduzidas novas concepções de dignidade, uma vez que na ótica religiosa os indivíduos não eram definidos em razão da vinculação com um Estado, mas com um único Deus. Nesse contexto, a noção de virtude estava relacionada ao Divino, e não à polis ou aos outros homens. Ademais, na concepção cristã, o ser humano, por si só, era incapaz de realizar o bem, de modo que necessitava do auxílio de Deus para tornar-se virtuoso (MORAES, 2010, p. 116).

Sobreveio, no Século XV, o célebre “Discurso sobre a Dignidade do Homem”, escrito por Giovanni Pico Della Mirandola (2006, p. XLIII-XLV), que centralizou o homem no mundo e foi considerado o documento fundamental do Renascimento. A ideia de dignidade humana foi construída a partir do poder de escolha do ser humano, realizado mediante a reflexão de suas ações. O "Discurso" ressaltou que a natureza dos outros seres estava refreada por leis escritas pelo homem que, por sua vez, não era constrangido por nenhuma limitação e poderia determiná-las segundo seu arbítrio, com o poder assegurado por Deus. A partir desse entendimento, Pico Della Mirandola (2006, p. 57) acentuou o livre arbítrio do homem. O antropocentrismo não afastava a presença Divina, porquanto entendia que o homem era uma criatura de Deus, do qual recebeu o lugar central no mundo e a liberdade para realizar as escolhas diante das possibilidades existentes, de modo que a dignidade consistia em saber usar a liberdade pelo uso da razão.

No Século XVI, o teólogo espanhol Francisco de Vitória (1974) situou a dignidade humana no âmbito social, político e jurídico. O autor analisou o processo de aniquilação, exploração e escravidão dos indígenas da América pelo colonizador espanhol. Nessa conjuntura, tratou a questão da igualdade por meio de uma abordagem jurídica, sob arguição de que o fato dos indígenas não serem cristãos, não significava que não tivessem direitos, na medida em que, em princípio, eram livres e iguais e, portanto, deveriam ser tratados como sujeitos de direitos (BARRETTO, 2013, p. 69).

Na filosofia moderna, o pensamento de Immanuel Kant (2009, p. 239-240 e 265) contribuiu de modo relevante na construção da ideia de dignidade humana. Em razão da teoria kantiana permear muitos aspectos da ideia contemporânea de dignidade humana, a mesma será objeto de reflexão no próximo tópico. Por ora, releva destacar de maneira simplista, que na concepção kantiana o ser humano é considerado como um fim em si mesmo, de modo que a pessoa deve ser tratada sempre como um fim e não como um simples meio, assim como que a dignidade não tem preço, isto é, não poderá ser substituída por qualquer coisa equivalente. 
No contexto da sociedade tecnocientífica contemporânea, Jürgen Habermas (2004, p. 46-47) apresenta a noção de dignidade humana no sentido moral e jurídico. O filósofo observa inicialmente que a comunidade de seres morais, que elaboram suas próprias leis, abrange todas as relações que necessitam de um regulamento normativo e somente os membros dessa comunidade podem impor mutuamente obrigações morais e esperar reciprocamente um comportamento de acordo com as normas. Nesse contexto, embora os animais sejam beneficiados pelas obrigações morais, uma vez que ao lidar com os mesmos o ser humano deve levar em conta as obrigações morais pois também são passíveis de sofrimento, mesmo assim os animais não pertencem ao universo dos membros que dirigem "uns aos outros" ordens e proibições reconhecidas intersubjetivamente. Desse modo, segundo Habermas, a dignidade humana encontra-se ligada a essa simetria das relações da comunidade de seres morais, que necessitam de um regulamento normativo. O filósofo salienta que a dignidade não é uma propriedade que se pode possuir por natureza como, por exemplo, a inteligência ou a cor dos olhos, mas é caracterizada por "aquela 'intangibilidade' que somente tem significado nas relações interpessoais de reconhecimento recíproco e no relacionamento igualitário entre as pessoas".

Segundo o filósofo contemporâneo Bernard Baertschi (2009, p. 188), a dignidade possui dois sentidos principais em sua acepção moral. O primeiro é pessoal, relacionado ao respeito do ser humano consigo mesmo, às suas condutas, de modo que se pode perder a dignidade. O segundo é impessoal, consiste no fato do indivíduo ser uma pessoa humana e não uma coisa, tem sentido ontológico, relacionado à natureza humana e, portanto, não possibilita a perda da dignidade. Nesse último sentido, ligado à concepção kantiana, a pessoa tem um valor particular, de modo que não pode ser tratada como um simples meio. Nesta perspectiva, respeitar a dignidade de alguém é tratá-lo como pessoa, que merece respeito e não pode ser instrumentalizada. Assim, Baertschi enfatiza que "a dignidade de um ser é função daquilo que ele é em si mesmo, quer dizer, de suas propriedades intrínsecas e essenciais: se dois seres possuem a mesma essência, eles têm a mesma dignidade; se sua essência é outra, eles não têm a mesma dignidade”.

Enfim, a dignidade humana pode ser caracterizada como um qualificativo do gênero humano ${ }^{4}$, por meio da qual é possível identificar todos os seres humanos como pertencentes a um mesmo gênero. Essa identificação, faz com que todos integrem a humanidade, que é o critério último do reconhecimento, porquanto são dotados de dignidade (BARRETTO, 2013, p. 66).

Portanto, é possível perceber, a ideia de dignidade humana acompanhou as transformações do ser humano e da sociedade. No passado mais distante, as mudanças ocorreram de forma gradativa, ao passo que no mundo contemporâneo são mais velozes e abrangentes, mormente em decorrência do desenvolvimento

\footnotetext{
${ }^{4}$ O termo gênero humano é empregado no presente artigo com o significado de espécie humana.
} 
tecnocientífico ${ }^{5}$, associado ao processo de globalização. Depreende-se, portanto, que não se trata de fixar um conceito de dignidade, mas de acompanhar o contínuo processo de construção, desconstrução e reconstrução da ideia de dignidade humana, de acordo com a realidade correspondente.

\section{A CONCEPÇÃO KANTIANA DE DIGNIDADE}

O pensamento de Immanuel Kant ${ }^{6}$ influenciou de modo expressivo a construção da ideia moderna de dignidade humana. Em que pese a sociedade tenha passado por grandes transformações desde a concepção kantiana de dignidade, especialmente em decorrência do progresso da ciência e da técnica, o pensamento de Kant permeia muitos aspectos da noção contemporânea de dignidade humana.

O humanismo moderno fundou-se, em grande parte, na filosofia kantiana, que considerou a modernidade como a chegada da humanidade à maioridade de sua consciência, no sentido do ser humano ter a liberdade de fazer uso do próprio entendimento e assumir seu destino mediante sua própria vontade. Kant entende que a liberdade torna possível o Iluminismo, isto é, a chegada do ser humano à maioridade de sua consciência. Assim, a autonomia ocupa lugar central no pensamento do filósofo (JUNGES, 2007, p. 84).

Deste modo, Kant promoveu uma verdadeira "revolução copernicana" e propôs princípios baseados na razão como instrumento do conhecimento e do agir humano. A máxima kantiana "Sapere aude!", isto é, "ouse saber" incentivou as pessoas a terem coragem de expressar sua inteligência e a raciocinarem antes de obedecer. A época do Iluminismo, para Kant, representou a liberdade do ser humano do estado de tutela em que se encontrava submetido, caracterizado em não fazer uso público da razão (BARRETTO, 2013, p. 42).

Assim, a filosofia kantiana é chamada de transcendental, na medida em que propõe a ideia do sujeito como centro do conhecimento, no sentido teórico e prático (MILOVIC, 2009, p. 498). Para construir sua teoria, Kant distingue os conhecimentos segundo sua origem, na razão ou na experiência, mediante os conceitos a priori e a posteriori. O filósofo alemão denomina a priorio conhecimento anterior a qualquer experiência e a posteriorio conhecimento oriundo da experiência (HÖFFE, 2005, p. 46-47). A teoria do conhecimento de Kant é baseada no conjunto de elementos a priori, que são intuições, categorias e princípios, que se caracterizam pelo caráter de necessidade rigorosa e de validade universal (BARRETTO, 2013, p. 43-48).

Kant elabora o imperativo categórico no sentido de um princípio a priori, para ser utilizado como lei universal nas ações humanas. O imperativo categórico, conforme explica Otfried Höffe (2005, p. 197-199),

\footnotetext{
${ }^{5} \mathrm{O}$ termo "desenvolvimento tecnocientífico" é utilizado como sinônimo dos avanços biotecnológicos e do progresso da ciência e da técnica, na medida em que a sociedade contemporânea vivencia um verdadeiro ciclo de descobertas e transformações, capazes de alterar o curso natural da vida e da natureza. (BARRETTO, 2013. p. 349.).
} 
consiste no conceito de moralidade, como do simplesmente bom, por isso um "imperativo" referido "categoricamente" a seres racionais finitos, na medida em que entes racionais necessitados não agem por si mesmos moralmente, de modo que a moralidade tem um caráter de dever-ser e não de um ser. Portanto, trata-se de modos de conduta considerados moralmente corretos, sem que tenham o significado de leis naturais.

O imperativo categórico não se refere a regras, mas a máximas, que consistem em proposições fundamentais do agir, que contêm uma determinação universal da vontade e dependem de regras práticas (HÖFFE, 2005. p. 203-204). O principal imperativo categórico encontra-se representado na seguinte máxima: "age apenas segundo a máxima pela qual possas ao mesmo tempo querer que ela se torne uma lei universal" (KANT, 2009.p. 215).

Kant formulou mais de um imperativo categórico e, com relação à dignidade humana, assume maior relevância a segunda formulação, no sentido de que o homem não deve ser meramente considerado como um meio, mas sempre como um fim em si mesmo. Nessa perspectiva, entre os principais textos, na Fundamentação da Metafísica dos Costumes, Kant afirma que:

o homem - e de modo geral todo ser racional - existe como um fim em si mesmo, não meramente como um meio à disposição desta ou daquela vontade para ser usado a seu belprazer, mas tem de ser considerado em todas as suas ações, tanto as dirigidas a si mesmo quanto a outros sempre ao mesmo tempo como fim (KANT, 2009. p. 239-240).

$\mathrm{Na}$ sociedade tecnocientífica, o princípio kantiano segundo o qual a pessoa deve ser tratada sempre como um fim e não como um simples meio, demonstra que a dignidade humana exige a não instrumentalização do ser humano. Assim, não é admitido, por exemplo, sacrificar a vida de uma pessoa para salvar outra que necessite de um órgão vital ou submeter um indivíduo a experiências científicas sem o seu consentimento (ANDORNO, 2009, p. 73-84).

A ideia contemporânea de dignidade humana, segundo Ingo Sarlet (2009, p. 214-220), busca seus fundamentos no pensamento kantiano, precipuamente no sentido de afastar a coisificação e instrumentalização do ser humano. Entretanto, conforme observa o mencionado autor, não quer dizer que o ser humano não possa servir espontaneamente para fins de terceiros, sem que venha a ser degradado na sua condição humana. $O$ fato, por exemplo, de prestar um serviço a outra pessoa, desempenhar função social ou doar um órgão sem prejuízo da própria saúde, não significa, por si só, que está a ferir a dignidade humana. Em muitas situações o critério para identificar o desrespeito à dignidade humana passa a ser o do objetivo da conduta, isto é, a intenção de instrumentalizar o ser humano.

No mesmo sentido, Tom Beauchamp e James Childress (2002, p. 74) esclarecem que o princípio

\footnotetext{
${ }^{6}$ Immanuel Kant nasceu em 22 de abril de 1724, em Königsberg (na Prússia), atual Kaliningrado (pertencente à Rússia), e faleceu em 12 de fevereiro de 1804. Filósofo alemão, foi um dos mais importantes pensadores dos tempos modernos. (MILOVIC, 2009, p. 498).
} 
kantiano não exige categoricamente que nunca se trate a pessoa como um meio para atingir determinados fins. Nesta perspectiva, não se pode tratar uma pessoa "exclusivamente" como um meio para atingir determinados fins. Por exemplo, é permitida a participação de pessoas em pesquisas científicas mediante consentimento livre e esclarecido e com observância dos fundamentos éticos e científicos. Portanto, conforme observam os mencionados autores, Kant não próbe o uso consentido das pessoas, mas insiste em que o ser humano seja tratado com respeito e dignidade moral à qual todos têm direito.

Na análise de José Roque Junges (2006, p. 125), a ideia central que transpassa a concepção kantiana de dignidade é o ser humano entendido como um fim em si mesmo. A pessoa é considerada um fim em si mesmo e não pode ser utilizada como um meio essencialmente em razão de que o ser humano, diferentemente dos demais seres, é uma realidade moral, na medida em que a cada um é dada a tarefa de realizar sua moralidade.

Outro aspecto de destaque na teoria kantiana consiste na ideia de que a dignidade não tem preço, isto é, não poderá ser substituída por qualquer coisa equivalente. Segundo Kant, o que se relaciona com as necessidades e inclinações humanas em geral possui um preço de mercado, mas o que constitui uma condição sob a qual apenas algo pode ser um fim em si, não tem meramente um valor relativo, ou seja, um preço, mas um valor intrínseco - a dignidade. Nesse sentido o filósofo acentua que:

No reino dos fins tudo tem ou bem um preço ou bem uma dignidade. O que tem preço, em seu lugar também se pode pôr outra coisa, enquanto equivalente, mas o que se eleva acima de todo preço, não permitindo, por conseguinte, qualquer equivalente, tem uma dignidade (KANT, 2009. p. 265).

A dignidade, portanto, é o contrário de preço, ela não tem equivalente, sua natureza é única e insubstituível. Kant (2009, p. 267) acentua que a dignidade está "infinitamente acima de todo preço, com o qual ela não pode de modo algum ser cotada e comparada, sem por assim dizer atentar contra sua santidade”. Assim, na sociedade existem duas categorias de valores: o preço e a dignidade. Enquanto o preço representa um valor exterior (de mercado) e manifesta interesses particulares, a dignidade consiste num valor interior (moral) e é de interesse geral. Portanto, as coisas têm preço e as pessoas têm dignidade (MORAES, 2010, p. 117).

$\mathrm{Na}$ teoria kantiana, as definições de dignidade estão relacionadas, precipuamente, às categorias de ser racional, homo noumenon, personalidade, fim em si mesmo, moralidade, autonomia e liberdade (BARRETTO, 2013, p. 71). Os respectivos conceitos evidenciam o núcleo da ideia de dignidade humana em Kant e encontramse, principalmente, nas obras "Fundamentação da Metafísica dos Costumes" e "Metafísica dos Costumes".

No que diz respeito ao ser racional, Kant (2009, p. 269-273) salienta que o ser humano é o único ser dotado de razão ${ }^{7}$ e pertence ao reino dos fins, que significa a ligação sistemática dos seres humanos por leis comuns, de modo que deverá agir pela vontade ou em obediência à lei, tratando a si mesmo e aos outros seres

\footnotetext{
7 "Ora, o homem encontra efetivamente dentro de si uma faculdade pela qual se distingue de todas as outras coisas, até de si mesmo na medida em que é afetado por objetos, e tal é a 'razão'” (KANT, 2009.p. 367).
} 
humanos como fins em si mesmos. ${ }^{8}$ A dimensão de universalidade do reino dos fins exige que as leis morais sejam observadas por todos os seres humanos, portanto, o ser humano produzirá leis às quais ele próprio deverá submeter-se. Assim, o agir humano deverá ser pautado pelo seguinte imperativo categórico: "age segundo a máxima que possa sempre fazer de si mesma uma lei universal".

Prosseguindo a lógica kantiana, a expressão homo noumenon tem origem na distinção entre o mundo sensível e o mundo inteligível. No primeiro, os seres são submetidos às leis da causalidade natural e no segundo às leis da razão. O ser humano é submetido como os demais seres às leis da natureza, entretanto, ele possui a faculdade que o diferencia dos demais seres que é a razão. Portanto, o ser humano pertence também ao mundo intelegível, de modo que é um noumeno, isto é, um fim em si mesmo (BARRETTO, 2013, p. 71-72).

O ser humano é pensado em termos de sua personalidade, isto é, como um ser dotado de liberdade interior, deverá observar as leis consigo mesmo e para com os outros seres humanos. A personalidade, na concepção kantiana, não reflete as necessidades e inclinações do mundo sensível, encontra-se inserida no contexto do mundo inteligível. Assim, a personalidade se expressa pela liberdade e independência em relação à natureza (KANT, 2003, p. 260-262).

A moralidade, na concepção kantiana, consiste na condição essencial para que o ser humano seja considerado como um fim em si mesmo e, portanto, tenha dignidade. Nesse sentido, Kant (2009, p. 263) acentua que a moralidade é a única condição sob a qual um ser racional pode ser fim em si mesmo, na medida em que somente por meio da moralidade é possível ser um membro legislante no reino dos fins.

Na definição de dignidade relacionada à moralidade, José Roque Junges (2007, p. 85) identifica três características, quais sejam: a incondicionalidade, em razão da absoluta prioridade; a superioridade absoluta, na medida em que está acima de qualquer preço; e a incomensurabilidade, no sentido de nenhum equivalente. Portanto, a dignidade humana identifica-se com a moralidade, isto é, "a dignidade humana é uma característica essencial da humanidade, através da moralidade”.

Por sua vez, a autonomia é definida como "a qualidade da vontade pela qual ela é uma lei para si mesma (independentemente de toda qualidade dos objetos do querer)". O princípio da autonomia da vontade consiste em "não escolher de outro modo senão de tal modo que as máximas de sua vontade também estejam compreendidas ao mesmo tempo como uma lei universal no mesmo querer", isto é, pela ideia de uma lei universal a vontade não se funda em nenhum interesse, na medida em que deve se reportar ao universo ético, que é incondicional. Assim, a autonomia da vontade consiste na faculdade do ser humano escolher, pela razão, agir de acordo com a lei, independentemente das inclinações pessoais, isto é, agir de acordo com o dever a partir da livre aceitação da lei moral (KANT, 2009, p. 285).

\footnotetext{
8 “Entendo, porém, por 'reino’ a ligação sistemática de diferentes seres racionais mediante leis comuns." (KANT, 2009. p. 259-261).
} 
No sistema kantiano, o conceito de liberdade é a chave para a explicação da autonomia da vontade. A vontade é uma espécie de causalidade em razão da racionalidade e, por sua vez, a liberdade é propriedade dessa causalidade na medida em que pode ser eficiente independentemente de causas alheias, assim como a necessidade natural seria a propriedade dos seres irracionais pela influência de causas alheias. Ademais, o conceito de causalidade traz consigo o conceito de leis, de modo que a liberdade não é totalmente alheia à lei, muito pelo contrário, é livre a manifestação de vontade regida pelas leis morais, do contrário, uma vontade livre seria uma coisa absurda (KANT, 2009, p. 285).

Assim, Kant (2009, p. 285) chega a uma definição de dignidade como sendo o resultado de uma sequência que inicia em considerar a pessoa como ser racional para defini-la como ser dotado de autonomia na liberdade. Portanto, a dignidade humana para Kant, consiste na faculdade da pessoa em estabelecer leis universais de comportamento as quais ela própria deve submeter-se.

Ultrapassada essa análise, releva notar ainda que na teoria kantiana a dignidade humana está relacionada ao respeito (KANT, 2009, p. 285). Na Doutrina da Virtude da "Metafísica dos Costumes", ao tratar dos deveres para com os outros, Kant (2003, p. 267-277) observa que "todo ser humano tem um direito legítimo ao respeito de seus semelhantes e, está, por sua vez, obrigado a respeitar todos os demais". Assim, a dignidade eleva os seres humanos acima de todos os demais seres do mundo e, deste modo, o ser humano tem a obrigação de reconhecer a dignidade humana e de respeitar a si mesmo e a todos os outros seres humanos.

Enfim, conforme observado inicialmente, expressiva parte da doutrina contemporânea identifica na concepção kantiana muitos aspectos da noção de dignidade humana. A partir do pensamento de Kant, busca-se bem compreender a ideia de dignidade humana no contexto da sociedade tecnocientífica, especialmente com relação aos perigos de instrumentalização do ser humano diante dos avanços biotecnológicos.

\section{O PRINCÍPIO DA DIGNIDADE DA PESSOA HUMANA}

Enquanto a ideia de que a pessoa tem uma dignidade é encontrada desde a antiguidade, a positivação do princípio da dignidade humana é relativamente recente. Somente a partir da Segunda Guerra Mundial, com algumas exceções de países que já haviam inserido o princípio da dignidade humana nos respectivos textos constitucionais, o valor fundamental da dignidade da pessoa humana passou a ser reconhecido nas Constituições dos Estados, mormente após a Declaração Universal dos Direitos Humanos (SARLET, 2012, p. 96-97).

De fato, foi somente depois da Segunda Guerra Mundial que a sociedade percebeu que as violações aos direitos humanos e à dignidade humana poderiam ser prevenidas se existisse um efetivo sistema de proteção. Como observa Flávia Piovesan (2012, p. 183-184), no momento em que os seres humanos tornaram-se supérfluos e descartáveis diante da lógica da destruição e da supressão do valor da pessoa humana, verificou-se a 
necessidade de reconstruir os direitos humanos, como um paradigma ético que aproximasse o Direito da moral.

Nesse contexto, a dignidade humana foi introduzida pela Assembleia Geral das Nações Unidas na Declaração Universal dos Direitos Humanos, de 1948. A Declaração fez referência expressa à dignidade da pessoa humana, tanto no seu Preâmbulo como no artigo $1^{\circ}$. A partir da positivação dos direitos humanos no contexto internacional, o princípio da dignidade da pessoa humana também passou a ser reconhecido nos ordenamentos jurídicos internos de grande parte dos países (SARLET, 2012.p. 97).

No Brasil, após mais de duas décadas de Ditadura Militar, a Constituição Federal de 1988 inseriu o princípio da dignidade da pessoa humana como um dos fundamentos da República (MORAES, 2010, p. 119). Desse modo, o mencionado princípio adquiriu posição central no ordenamento jurídico brasileiro que, como Estado Democrático de Direito, passou a adotá-lo não somente no âmbito constitucional, mas como base e referência no sistema jurídico.

A Ministra Cármen Lúcia Antunes Rocha (2008), na Ação Direta de Inconstitucionalidade n 3.510, acentua que o princípio da dignidade da pessoa humana não caracteriza somente a modificação parcial dos textos fundamentais dos Estados contemporâneos, porquanto se trata de um novo momento do Direito Constitucional, que tem como fundamento o valor supremo da dignidade da pessoa humana. Antes, eram estabelecidos modelos de comportamento impostos para a ação do Estado e a conduta dos indivíduos, agora são estatuídos princípios que informam os preceitos constitucionais ou legais, a partir dos quais são realizados os fins postos como próprios pelo povo no seu sistema fundamental.

Portanto, a partir da introdução do princípio da dignidade da pessoa humana pela Constituição, foi expressamente reconhecido que é o Estado que existe em função da pessoa humana, e não o contrário, na medida em que o indivíduo constitui a finalidade precípua e não meio da atividade estatal (SARLET, 2012, p. 98). Tornou-se, assim, fundamental o referido princípio no Estado Democrático de Direito.

É premente observar ainda, que ocorreu uma transposição das normas do sistema de Direito Civil, constantes no texto do Código Civil, para a Constituição Federal. Esse aspecto levou a consequências jurídicas decisivas no sentido do deslocamento da tutela, que até então era oferecida pelo Código Civil ao indivíduo, para a proteção, pela Constituição da República, à dignidade da pessoa humana, como fundamento da República

\footnotetext{
${ }^{9}$ A Declaração Universal dos Direitos Humanos dispõe em seu Preâmbulo:

Considerando que o reconhecimento da dignidade inerente a todos os membros da família humana e de seus direitos iguais e inalienáveis é o fundamento da liberdade, da justiça e da paz no mundo.

(...)

Considerando que os povos das Nações Unidas reafirmaram, na Carta, sua fé nos direitos humanos fundamentais, na dignidade e no valor da pessoa humana e na igualdade de direitos dos homens e das mulheres, e que decidiram promover o progresso social e melhores condições de vida em uma liberdade mais ampla.

E, prossegue, estabelecendo no Artigo I:
} 
Federativa do Brasil (MORAES, 2010, p. 119).

Assim, o princípio da dignidade da pessoa humana busca garantir o respeito e a proteção da dignidade não somente no sentido de assegurar um tratamento humano e não degradante e de garantias à integridade física do ser humano. Em razão do caráter normativo dos princípios constitucionais, o princípio da dignidade da pessoa humana é dotado de valores éticos e jurídicos decorrentes do Estado Democrático de Direito, do que resulta a mencionada transformação do Direito Civil, que deixa de ser um Direito com fundamento em valores individualistas e passa a tutelar a dignidade da pessoa humana (MORAES, 2010, p. 119).

A constitucionalização do princípio da dignidade da pessoa humana, segundo Cármen Lúcia Rocha (2008), transforma toda a construção jurídica. A expressão do referido princípio como fundamento do Estado Democrático de Direito significa que restarão asseguradas as condições políticas, sociais, econômicas e jurídicas para que o ser humano atinja seus fins. A propósito, mais do que a pessoa humana, os sistemas constitucionais e as declarações internacionais passaram a considerar a dignidade humana como princípio.

Entretanto, o princípio da dignidade da pessoa humana nem sempre tem sido acompanhado por uma reflexão acerca dos seus fundamentos ético-filosóficos. A ausência dessa análise sobre tema tão relevante pode gerar o emprego indiscriminado do princípio para tudo abranger e justificar. Na medida em que se encontra como primeiro princípio da Constituição, fonte de todos os demais, deve permanecer subsidiário, de modo sua aplicação deverá restringir-se às questões em que nenhum outro princípio ou conceito jurídico possa ser utilizado, sob pena de ocorrer uma dissolução de todo Direito na dignidade humana. O uso indiscriminado do princípio da dignidade da pessoa humana torna-o onipresente, mesmo quando a lei específica atende às necessidades da tutela jurídica. Assim, tudo passaria a ser questão de dignidade humana, de modo que o sistema jurídico se esvaziaria de qualquer sentido normativo (BARRETTO, 2013, p. 63 e 67).

A afirmação de que todos os direitos fundamentais encontram seu fundamento no princípio da dignidade humana e que este pode ser considerado o elemento comum aos respectivos direitos deve ser vista com certa reserva. Por primeiro, em razão de ser passível de discussão a qualificação do princípio da dignidade da pessoa humana como um direito fundamental autônomo, não obstante sua importante função como elemento referencial para a aplicação e interpretação dos direitos fundamentais ou na condição de fundamento para a dedução de direitos fundamentais decorrentes. E, ainda, considerando o extenso catálogo de direitos fundamentais, há dúvidas no sentido de que todos possuem necessariamente um conteúdo com base no valor maior da dignidade humana. Portanto, é necessária uma compreensão prévia do significado e do conteúdo do princípio da dignidade da pessoa humana, assim como de sua eficácia jurídica (SARLET, 2012, p.95-96).

Todas as pessoas nascem livres e iguais em dignidade e direitos. São dotadas de razão e consciência e devem agir em relação umas às outras com espírito de fraternidade. (NAÇÕES UNIDAS NO BRASIL. Declaração Universal dos Direitos Humanos). 
Na mesma linha de raciocínio, Maria Celina Bodin de Moraes (2010, p. 120) salienta que a noção de dignidade humana é ampliada por infinitas conotações que levam ao risco da generalização absoluta. Para que sejam extraídas consequências jurídicas do princípio da dignidade da pessoa humana torna-se necessário retomar os postulados filosóficos. Nesse quadro teórico, a autora assinala a relevância da teoria kantiana, norteadora da noção de dignidade como valor intrínseco da pessoa humana.

Portanto, com base na relevante doutrina acerca do tema, verifica-se que para a efetividade do princípio da dignidade da pessoa humana torna-se preciso uma compreensão prévia do seu conteúdo e, para tanto, é necessária a busca por sua concepção filosófica, de modo a assegurar a transição lógico-conceitual para plano jurídico-constitucional. O conteúdo do princípio da dignidade humana pode ser desdobrado em duas máximas: "não tratar a pessoa como simples meio e assegurar as necessidades vitais da pessoa humana" (BARRETTO, 2013, p. 74-75).

A primeira máxima, que tem origem no imperativo categórico de Kant, estabelece que a pessoa não pode ser utilizada como um simples meio da vontade de outra pessoa, mas como um fim em si mesma, de modo que o princípio da dignidade humana pretende impedir a instrumentalização da pessoa. A segunda máxima significa que o princípio da dignidade humana exige que o ser humano não seja tratado como um espírito puro, considerando que é um ser encarnado em um corpo físico com necessidades que deverão ser atendidas. Portanto, a dignidade humana exige também acesso aos cuidados de saúde, moradia, trabalho, educação, etc. (BARRETTO, 2013, p. 74-75).

No que diz com a natureza jurídica do princípio da dignidade da pessoa humana, não se trata de um direito subjetivo, todavia, pode exigir que esses direitos sejam reconhecidos para o indivíduo. Portanto, o princípio da dignidade da pessoa humana constitui um direito que surge em função da necessidade de reconhecimento de outros direitos, situados além dos direitos individuais (BARRETTO, 2013, p. 76).

O princípio da dignidade da pessoa humana não impõe apenas um dever de abstenção, isto é, de respeito, mas também de condutas positivas para proteger e efetivar a dignidade do indivíduo. Assim, incumbe ao Estado abster-se de ingerências contrárias à dignidade humana, impondo um dever de respeito e proteção, assim como de proteger a pessoa humana contra agressões de terceiros. Do mesmo modo, compete aos órgãos estatais a edificação de uma ordem jurídica que corresponda às exigências do princípio. Além do conteúdo ético e moral, o princípio da dignidade da pessoa humana consiste em norma jurídico-positiva dotada de eficácia, caracterizado como o princípio constitucional de maior hierarquia axiológico-normativa (SARLET, 2012, p. 106-107).

O voto do Ministro Ayres Britto (2008), na Ação Direta de Inconstitucionalidade n³.510, ilustra o acima referido, quando enfatiza que "a dignidade da pessoa humana é princípio tão relevante para a nossa Constituição que admite transbordamento". Nessa linha de raciocínio, o Ministro Relator discorre sobre o 
alcance do princípio constitucional da dignidade da pessoa humana para o reconhecimento de algum grau de proteção ao embrião e ao feto, em face do silêncio dos dispositivos e demais princípios constitucionais sobre a questão.

Em síntese, o princípio da dignidade da pessoa humana adquiriu relevância no contexto internacional e interno dos Estados a partir da Segunda Guerra Mundial, principalmente após a introdução da dignidade humana na Declaração dos Direitos Humanos. No Brasil, somente a partir da Constituição Federal de 1988 o princípio da dignidade da pessoa humana adquiriu posição central no ordenamento jurídico. Entretanto, se por um lado a importância atribuída ao princípio da dignidade da pessoa humana tem o condão de refletir positivamente nas demais searas jurídicas, de outro, o uso indiscriminado do princípio e o elevado grau de abstração do seu conteúdo, levam ao esvaziamento de sua relevância. Desse modo, a doutrina jurídica mais expressiva acerca do tema indica um retorno aos seus fundamentos ético-filosóficos, de modo a buscar a compreensão e a correta interpretação do princípio da dignidade da pessoa humana, em busca de sua efetividade.

\section{A DIGNIDADE HUMANA NO PLANO JURÍDICO-CONSTITUCIONAL}

A dignidade humana constitui o valor maior de referência em grande parte dos sistemas jurídicos nas sociedades democráticas hodiernas. Em que pese sua relevância, uma definição do que efetivamente seja a dignidade humana tem sido difícil de ser obtida, na medida em que se trata de um "conceito com contornos vagos e imprecisos". Entretanto, não pairam dúvidas no sentido de que embora não seja clara, a dignidade é real, de modo que a doutrina e a jurisprudência passaram a estabelecer alguns delineamentos basilares à noção de dignidade humana em busca da concretização de seu conteúdo (SARLET, 2012, p. 100).

A dignidade humana, conforme observa Roberto Andorno (2009, p. 81-82), ainda que dificilmente definível, é uma característica real do ser humano, que precede e fundamenta o ordenamento jurídico em seu conjunto. Dito de outro modo, a raiz de todos os direitos é a dignidade inerente ao ser humano. Em que pese a dificuldade de definição da dignidade humana, é possível uma aproximação conceitual, no sentido de um valor único e incondicional que tem a existência dos seres humanos, independentemente de qualquer qualidade acessória correspondente a origem étnica, sexo, idade, estado de saúde, condição social, econômica ou religiosa.

Entretanto, por conta dos riscos à identidade e à existência da humanidade que decorrem do desenvolvimento da ciência e da tecnologia, a dignidade humana a ser compreendida tanto com relação aos indivíduos da sociedade contemporânea, quanto às gerações futuras. A noção extensiva decorre do fato de que se cada ser humano possui um valor intrínseco, o gênero ao qual pertence, isto é, a humanidade, também tem um valor inerente. Deste modo, o amplo conceito de dignidade abrange a proteção da integridade e da identidade do gênero humano, assim como a preservação do ambiente sustentável para a geração futura (ANDORNO, 2009, p. 
$81-82)$

A seu turno, Ingo Sarlet (2009, p. 223) elabora uma proposta de conceituação jurídica de dignidade humana sob a perspectiva ontológica e instrumental, destacando, de um lado, sua característica intersubjetiva e, de outro, a dimensão defensiva e prestacional. Assim, Sarlet define a dignidade humana como a qualidade intrínseca e distintiva reconhecida em cada ser humano que o faz merecedor do mesmo respeito e consideração por parte do Estado e da comunidade. Implica, assim, em um complexo de direitos e deveres fundamentais que assegurem a pessoa tanto contra todo e qualquer ato de cunho degradante e desumano como venham a the garantir as condições existenciais mínimas para uma vida saudável. Propicia e promove sua participação ativa e coresponsável nos destinos da própria existência e da vida em comunhão com os demais seres humanos.

A dignidade, como qualidade intrínseca da pessoa humana "é algo que simplesmente existe, sendo irrenunciável e inalienável, na medida em que constitui elemento que qualifica o ser humano como tal e dele não pode ser destacado" (SARLET, 2012, p. 101). Note-se que a dignidade é uma qualidade inerente a todas as pessoas humanas e, considerando que não existem graduações de dignidade humana, todos os seres humanos são iguais em dignidade.

Ao discorrer sobre a dignidade humana no plano jurídico-constitucional, Cármen Lúcia Antunes Rocha (2008) observa que somente é possível concretizar a Justiça na medida em que a dignidade for atendida em sua plenitude com relação humanidade. A dignidade, segundo a Ministra Cármen Lúcia, é mais um dado jurídico do que uma construção acabada no Direito, na medida em que se (re)afirma no sentimento de justiça de cada povo para realizar suas vocações e necessidades, na medida em que toda pessoa humana é digna. A humanidade tem uma dignidade, contida na ética da espécie. Essa singularidade fundamental e insubstituível é ínsita à condição do ser humano, qualifica-o nessa categoria e o põe acima de qualquer indagação.

De outra parte, em virtude dos novos desafios éticos e jurídicos, que ultrapassam as fronteiras nacionais e envolvem toda a humanidade, começaram a surgir na legislação constitucional conceitos com pretensões de universalidade, como o conceito de dignidade da pessoa humana e dos direitos humanos (BARRETTO, 2013, p. 176). Assim, surgiu a problemática da dignidade humana no contexto multicultural, na medida em que muitos atos considerados contrários à dignidade humana para a maior parte da humanidade são considerados legítimos em determinadas comunidades ou mesmo situações consideradas normais em determinadas culturas são consideradas atos atentatórios à dignidade humana para a maioria da humanidade.

O mundo não é imóvel e as descobertas científicas e novas tecnologias resultantes renovam o debate sobre a dignidade humana. Desse modo, cada cultura é obrigada a aprofundar-se em busca de respostas de acordo com seus referenciais. Assim, ao lado da instabilidade decorrente das incertezas científicas, ocorre um conflito entre as convicções culturais contraditórias (DELMAS-MARTY, 2009, p. 366). 
É necessário, portanto, um parâmetro moral para nortear a ação humana que, na construção kantiana consiste no imperativo categórico. O imperativo categórico de Kant relativo à dignidade humana exige que o homem não seja tratado como um meio, mas sempre como um fim em si mesmo (KANT, 2009, p. 239-240). Os valores que permeiam as diferentes culturas deverão ser analisados por critérios racionais, definidos pelo imperativo categórico, para verificar quais originam-se da experiência sociocultural objetiva, representando características comuns aos seres humanos, que permitirão avaliar as relações com as diferentes realidades culturais. Trata-se, portanto, de encontrar um ponto de equilibrio racional entre os valores universais e a diversidade cultural (BARRETTO, 2013, p. 256).

A partir da reformulação do imperativo categórico kantiano, Habermas (1989, p. 86) elabora o princípio da universalização. A diferença consiste na superação do caráter puramente monológico do pensamento de Kant, que no pensamento habermasiano passa para uma interpretação dialógica do imperativo categórico. Portanto, enquanto em Kant a intersubjetividade da validade das leis morais, admitida a priori, permite a redução do agir ético à ação individual, em Habermas a universalização das leis morais é necessariamente um processo de diálogo, que envolve a participação das pessoas que podem ser atingidas pelas normas.

Por sua vez, Ingo Sarlet (2009, p. 224) assinala a ideia de uma comunidade inclusiva, pautada pelo multiculturalismo e contrária a qualquer concepção fixista ou reducionista de dignidade humana, em face do pluralismo e da diversidade de valores nas sociedades democráticas contemporâneas. Segundo o mencionado autor, um dos papeis principais do Direito e da Filosofia do Direito consiste em assegurar, mediante a adequada construção e compreensão da noção de dignidade humana, a superação de posições unilaterais, de modo a promover a proteção da dignidade de todas as pessoas em todos os lugares.

Nesse contexto, podem ser delineados alguns caminhos para garantir a integridade dos valores universais e permitir a manifestação da diversidade cultural. O primeiro consiste na escolha do mínimo moral, que afirma a necessidade de proteger o ser humano para que ele seja respeitado pelo Estado, grupos sociais e outros indivíduos (garantias negativas) e lhe sejam assegurados os bens básicos (garantias positivas). O segundo aponta para a necessidade de que os valores universais e gerais sejam expressos por sistemas normativos. Por exemplo, proibição da tortura, de genocídio, do uso da pessoa como objeto de pesquisas que afetem o sistema biológico, psicológico ou espiritual do ser humano. $O$ terceiro requer o cuidado em não confundir valores com mecanismos institucionais específicos, isto é, tanto no capitalismo como em outros sistemas o princípio da dignidade humana deve ser respeitado. $\mathrm{O}$ quarto procedimento consiste em enfrentar o desafio de que a sociedade é moralmente livre para formular normas dos valores universais, de modo que não podem ser condenadas em virtude de normas diferentes das aceitas nas demais sociedades. E, finalmente, o fortalecimento de diálogos regionais e interculturais (BARRETTO, 2013, p. 256-258). 
Como é possível observar, a dignidade humana constitui o núcleo da ordem jurídica contemporânea. Em que pese sua importância, tem-se encontrado dificuldades para defini-la claramente no plano jurídicoconstitucional, de modo que a doutrina e a jurisprudência buscam estabelecer algumas aproximações para sua compreensão e concretização. Entretanto, verifica-se que a dignidade humana não pode ser compreendida de modo fechado ou reducionista. É preciso que a noção de dignidade humana no âmbito jurídico-constitucional seja (re)construída com base em um conjunto de valores, que abrangem desde os fundamentos filosóficos até os aspectos jurídicos, éticos e multiculturais da sociedade. Assim, estar-se-á buscando efetivamente a concretização da dignidade humana no âmbito jurídico-constitucional, para fazer frente à velocidade e abrangência das transformações tecnocientíficas, assim como dos aspectos multiculturais das sociedades democráticas hodiernas.

\section{A DIGNIDADE HUMANA NA ERA BIOTECNOLÓGICA}

É inegável a importância do progresso da ciência e da técnica, especialmente no que diz respeito aos avanços da biomedicina. Todavia, os respectivos resultados não estão isentos de riscos à pessoa humana e à sua dignidade, mormente frente ao paradoxo da velocidade da biotecnologia e da ausência de parâmetros éticos e jurídicos com relação ao assunto.

Ao tratar dos valores básicos da existência humana, John Finnis (2007, p. 89-91) afirma que todas as sociedades humanas demonstram preocupação com o valor da vida humana. O primeiro valor básico do ser humano consiste no impulso da autopreservação, isto é, o valor da vida. O termo "vida" significa cada aspecto da vitalidade ( vita, vida) que põe o ser humano em boa forma para a autodeterminação. A vida inclui a saúde corporal e a ausência de dor (porquanto esta indica o mau funcionamento do organismo ou um dano orgânico), assim como a propagação da vida pela procriação. Portanto, as questões relacionadas ao início da vida humana, especialmente no contexto da sociedade tecnocientífica, assumem crescente relevância, na medida em que representam valor básico da humanidade.

Nessa perspectiva releva notar que entre os bens humanos básicos listados por John Finnis (2007, p. 105), encontra-se o bem da razoabilidade prática. A razoabilidade prática exige, em caráter efetivo, a prática, a atuação e a preocupação. É necessária a presença de uma consciência voltada à decisão e ao enfrentamento de uma eventual deficiência na sua construção. Não se trata simplesmente de uma tomada de decisão, mas de uma ação que possa justificar a atitude de acordo com os padrões humanamente aceitáveis. O objetivo desse bem humano é a utilização adequada da inteligência humana (ENGELMANN, 2007, p. 146-160), uma vez que o modo como será aplicado o raciocínio prático em projetos, disposições e ações, levará ao resultado da participação da pessoa nos demais bens básicos. Segundo Finnis (2007, p. 105-106), a ética consiste numa expressão dessa participação e das soluções consideradas razoáveis, considerando as reflexões sobre o passado e 
sobre um possível futuro.

No que diz com os avanços da biotecnologia, a necessidade de equilíbrio requer outra exigência da razoabilidade prática, conforme assinala Wilson Engelmann (2007, p. 169), qual seja, a relevância das consequências. De fato, é preciso que as ações do ser humano sejam avaliadas, levando em consideração a adequação do objetivo, a utilidade e as consequências. Nesse ponto, surge a questão das opções entre as diversas possibilidades, entre as quais sempre devem ser preferidos os bens humanos básicos (como a vida) aos bens meramente instrumentais (a propriedade).

Conforme observa Conill Sancho (2014), as novas tecnologias invadiram todos os âmbitos da vida privada, pública e social. Desse modo, não há praticamente nenhuma atividade humana que não esteja sendo afetada pelas tecnologias. Diante do progresso da técnica em todos os âmbitos, inclusive em sua determinação da razoabilidade prática, é necessário refletir e propor perspectivas que, ao mesmo tempo em que valorizam as contribuições tecnológicas, promovem uma orientação responsável com relação ao seu crescente poder.

A revolução tecnológica redimensionou as relações dos seres humanos com a natureza, as relações dos seres humanos entre si e a relação do ser humano consigo mesmo. Essas mudanças desenvolveram melhorias nas condições vitais da humanidade, contribuindo para reforçar o exercício de determinados direitos. Mas, por outro lado, determinados usos e abusos tecnológicos geram graves ameaças ao ser humano, o que tem exigido a formulação de novos direitos ou atualização e adequação dos direitos existentes aos novos desafios (PÉREZ LUÑO, 2012, p. 17).

Com efeito, cumpre indagar acerca da ética presente no contexto contemporâneo, assim como o significado das transformações decorrentes da técnica para o ser humano e suas possibilidades e limites. Essa indagação tem relevância na medida em que a tecnologia está transformando o próprio modo do ser humano entender-se a si mesmo (CONILL SANCHO, 2014).

Como bem assevera Judith Martins-Costa (2009, p. XI), há muito se acentua o paradoxo dos avanços biotecnológicos, na medida em que o desenvolvimento científico delineia um cenário ao mesmo tempo fascinante e perturbador. Desse modo, na agenda dos problemas que permeiam a sociedade contemporânea, encontram-se as novas tecnologias e seus impactos na tutela da pessoa humana. Para Gustavo Tepedino (2009, p. 22-23), a questão diz respeito à "exaustão das categorias jurídicas tradicionais diante da revolução tecnológica, que introduz novos interesses e bens jurídicos insuscetíveis de serem tratados com base nos paradigmas do passado." Paradoxalmente, ao lado dos grandes benefícios que as novas descobertas científicas trazem para a humanidade, acarretam igualmente um potencial danoso. Portanto, ao sistema jurídico cumpre o desafio de incentivar os novos horizontes da ciência e da técnica, sem, contudo, perder de vista a promoção da pessoa humana.

Nesse contexto, Hans Jonas (2006, p. 57) elabora uma proposta ética por meio do princípio 
responsabilidade, que assinala a necessidade de que a conduta da pessoa humana seja compatível com o futuro da humanidade. Dito de outro modo, as novas formas do agir humano mediante o uso da técnica requerem limites, na medida em que podem interferir no próprio ser humano e nas outras gerações. Portanto, é preciso abranger as situações decorrentes das obras do homo faber na era da técnica, mediante um compromisso com a dignidade humana e o futuro da humanidade.

Por sua vez, Roberto Andorno (2009, p. 83-84) assinala que "a noção de dignidade humana desempenha o papel de ideia diretriz da ética biomédica" e que a formulação kantiana de dignidade humana tem grande utilidade e facilita a busca de respostas aos problemas bioéticos. Trata-se, essencialmente, do imperativo categórico de Kant (2009, p. 239-265) no sentido de que a pessoa deve ser tratada sempre um fim em si e não como um simples meio e da teoria kantiana no sentido de que a dignidade não tem preço, isto é, não tem equivalente, pois sua natureza é única e insubstituível.

A perspectiva kantiana de não instrumentalização da pessoa humana, conforme enfatiza Andorno (2009, p. 84), é muito esclarecedora no âmbito dos novos conhecimentos científicos e biotecnológicos. Na esteira desse entendimento, o princípio da dignidade da pessoa humana significa, por exemplo, que não é possível sacrificar a vida de uma pessoa para salvar a vida de outra que necessita de um órgão vital; que não se pode submeter alguém a pesquisas científicas sem o seu consentimento ou quando os respectivos experimentos põem em perigo sua vida; que não se pode forçar uma pessoa a vender um órgão para atender as necessidades financeiras de sua família; entre tantos outros exemplos que poderiam ser citados no âmbito bioético. Desse modo, mediante o pressuposto da não-instrumentalização da pessoa, é possível fixar alguns limites éticos às intervenções da biotecnologia no ser humano.

Portanto, a sociedade contemporânea, permeada por incertezas em decorrência dos crescentes avanços tecnocientíficos, propugna pela dignidade humana por meio de uma ética responsável. A possibilidade de inserção da dignidade humana no surgimento das novas tecnologias será viável se forem consideradas as peculiaridades de cada situação concreta, mormente por estar diante de um conceito aberto, vulnerável à evolução da sociedade e ao entendimento dos juristas (ENGELMANN, 2014, p. 25).

A Constituição Federal prevê que o Estado promoverá e incentivará o desenvolvimento da pesquisa, da ciência e da tecnologia. Portanto, a liberdade de expressão e o desenvolvimento da ciência e da tecnologia encontram-se inseridos constitucionalmente como direitos da pessoa humana, todavia, deverão ser compatibilizados com os princípios constitucionais fundamentais, especialmente da dignidade humana, de modo que ocorra uma convergência entre a liberdade e a dignidade da pessoa humana.

Na Ação Direta de Inconstitucionalidade n 3.510, a Ministra Cármen Lúcia (2008) assinala que a liberdade de expressão da atividade intelectual e científica é considerada um dos fundamentos constitucionais, 
assim como o desenvolvimento científico e a pesquisa que podem levar à melhoria da qualidade de vida para todos. Torna-se necessária a compatibilização das respectivas regras com os princípios constitucionais fundamentais, assegurada sempre a dignidade humana.

A propósito, como bem assevera Andorno (2009, p. 74) "a liberdade é uma das faculdades que mais caracteriza o ser humano e está na raiz mesma de sua dignidade intrínseca”. Enquanto os demais seres vivos são condicionados pelo instinto, o ser humano tem a capacidade de decidir por si mesmo, mediante o uso da razão, de modo que tem a liberdade de escolher a conduta a seguir. Não se trata de agir deliberadamente, sem limites, na medida em que a liberdade deve ser coordenada pelo uso da razão, de modo que não faculta o ser humano a agir de modo irracional ou arbitrário, em detrimento dos demais.

É imprescindível uma convergência entre a liberdade da ciência e a dignidade humana (ANDORNO, 2009, p. 74-91). A liberdade científica e a dignidade humana podem (e devem) se relacionar de modo harmônico, entretanto, é preciso que essa liberdade esteja condicionada a parâmetros éticos e jurídicos, de modo que seja oportunizado o desenvolvimento da ciência e da tecnologia e, ao mesmo tempo, assegurada a dignidade humana. Enfim, o grande desafio da sociedade tecnocientífica consiste em entender a dignidade humana como pressuposto fundamental, a servir como princípio em torno do qual buscamos responder sobre o tipo de pessoa que queremos ser e a sociedade que pretendemos construir (BARRETTO, 2009, p. 20).

Denota-se, portanto, a importância da dignidade humana como referencial na reflexão, no debate e na construção de parâmetros éticos e jurídicos para nortear os avanços tecnocientíficos. Do contrário, corre-se o risco de transformar-se em realidade o hipotético "Admirável Mundo Novo" (HUXLEY, 1979), pensado por Aldous Huxley há tantas décadas. Na verdade, o que buscamos é que a sociedade tecnocientífica seja um mundo desejável, onde a ciência e a técnica estejam em equilíbrio com a vida e a dignidade humana.

\section{CONSIDERAÇÕES FINAIS}

A noção de dignidade humana acompanhou as transformações dos valores da sociedade. No passado mais distante, as mudanças ocorreram de forma gradativa, ao passo que no mundo contemporâneo as mutações são mais velozes e abrangentes, mormente em decorrência do progresso da ciência e da tecnologia.

Diante deste contexto, verificou-se a importância de refletir e compreender o contínuo processo de (re)construção da ideia de dignidade humana de acordo com a realidade correspondente. Ademais, a dignidade humana não pode ser compreendida de modo fechado ou reducionista e, nem tampouco aplicada de modo generalizado para tudo abranger e justificar. É preciso observar o conjunto de valores, que abrange desde os fundamentos filosóficos até os aspectos jurídicos, éticos e multiculturais da sociedade.

Assim, estar-se-á buscando a efetividade da dignidade humana como um referencial para os desafios 
decorrentes das crescentes transformações. Torna-se possível, assim, acompanhar e debater de modo mais consistente as questões advindas da mudança de valores do ser humano e da sociedade, especialmente diante da velocidade e abrangência dos avanços da ciência e da tecnologia, de modo a desvelar o sentido das normas existentes e construir parâmetros éticos e jurídicos para nortear as respectivas situações, com respeito à dignidade humana.

\title{
THE (RE) CONSTRUCTION OF THE IDEA OF HUMAN DIGNITY
}

\begin{abstract}
Human dignity is considered to be a base and a point of reference in contemporary law. Despite its relevance and its establishment in international declarations and in an expressive number of constitutional systems, the lack of understanding of the idea of dignity and the changing of society's values may cause a reductionist or even indiscriminate use of the principle of human dignity, thus losing its own sense in the legal system. This paper therefore aims to investigate the notion of human dignity, considering the changes in society, especially those promoted by scientific and technological progress during the last decades. The research method applied is the critical hermeneutic ethics approach, according to which ethics is the center of the process of understanding and interpretation, while observing the contours of facticity. As a result, it was found that it is essential, for the sake of the effectiveness of human dignity as a hermeneutic framework (especially in the context of fast and comprehensive changes caused by technoscientific advances), to reflect on and understand the ongoing process of (re)construction of the idea of human dignity, based on a set of values which covers societies' philosophical, legal, ethical and multicultural foundations.
\end{abstract}

Keywords: Human dignity. Social change. Technoscientific development. Ethics. Law.

\section{REFERENCIAS}

ANDORNO, Roberto. "Liberdade" e "Dignidade" da pessoa: dois paradigmas opostos ou complementares na bioética? In.: MARTINS-COSTA, Judith; MÖLLER, Letícia Ludwig (Org.). Bioética e Responsabilidade. Rio de Janeiro: Forense, 2009, p. 73-93.

AQUINO, Tomás de. Suma Teológica. v. 1,2. ed. São Paulo: Loyola, 2003.

Suma Teológica. v. 2. São Paulo: Loyola, 2002.

BAERTSCHI, Bernard. Ensaio filosófico sobre a dignidade. Trad. Paula Silvia Rodrigues Coelho da Silva. São Paulo: Loyola, 2009.

BARRETTO, Vicente de Paulo. O fetiche dos direitos humanos e outros temas. 2. ed. Porto Alegre: Livraria do Advogado, 2013.

Bioética, responsabilidade e sociedade tecnocientífica. In.: MARTINS-COSTA, Judith; MÖLLER, Letícia Ludwig (Org.). Bioética e Responsabilidade. Rio de Janeiro: Forense, 2009, p. 1-22.

BEAUCHAMP, Tom L.; CHILDRESS, James F. Princípios de ética biomédica. São Paulo: Loyola, 2002.

BOÉCIO. Sobre la persona y las dos naturalezas. In.: FERNÁNDEZ, Clemente. Los filosofos medievales: 
selección de textos. Madrid: BAC, 1979.

BRASIL. Constituição (1988). Constituição da República Federativa do Brasil de 1988. Disponível em: <http://www.planalto.gov.br/ccivil_03/constituicao/constituicao.htm>. Acesso em: 27 jan. 2016.

Supremo Tribunal Federal. Ação Direta de Inconstitucionalidade $n^{\circ} 3510$ Distrito

Federal.

Requerente: Procurador-Geral da República. Requerido: Presidente da República, Congresso Nacional. Relator:

Ministro Ayres Britto. Brasília, DF, 29 de maio de 2008. Disponível em: <http://redir.stf.jus.br/paginadorpub/paginador.jsp?docTP=AC\&docID=611723>. Acesso em: 15 jan. 2016.

CONILL SANCHO, Jesús. Hoje a grande ideologia é a ciência e a técnica. Revista do Instituto Humanitas Unisinos. São Leopoldo: Unisinos, n. 457, p. 31-33, 2014. Disponível em: http://www.huonline.unisinos.br/impressa/> Acesso em: 5 nov. 2015.

A manutenção da subjetividade humana diante do impulso tecnocientífico instrumental. [20 de outubro de 2014]. Entrevistadores: Márcia Junges e Ricardo Machado. Disponível em: http://www.ihu.unisinos.br/index.php?option=com_content\&view=article\&id $+5719 \&$ secao+456>. Acesso em: 5 nov. 2015. Entrevista concedida ao IHU Online.

Ética hermenéutica: crítica desde la facticidad. 2. ed. Madrid: Tecnos, 2010.

DELMAS-MARTY, Mireille. O universalismo dos direitos humanos em questão - o exemplo do direito à vida. In.: TEIXEIRA, Anderson V., OLIVEIRA, Elton Somensi de (Org.). Correntes contemporâneas do pensamento jurídico. Barueri: Manole, 2009.

ENGELMANN, Wilson; BORGES, Isabel Cristina Porto; GOMES, Taís Ferraz. Responsabilidade civil e nanotecnologias. São Paulo: Atlas, 2014.

Direito Natural, Ética e Hermenêutica. Porto Alegre: Livraria do Advogado, 2007.

FINNIS, John. Lei natural e direitos naturais. Trad. Leila Mendes. São Leopoldo: Unisinos, 2007.

HABERMAS, Jürgen. O futuro da natureza humana: a caminho de uma eugenia liberal? Trad. Karina Janinni. São Paulo: Martins Fontes, 2004.

HÖFFE, Otfried. Immanuel Kant. São Paulo: Martins Fontes, 2005.

HUXLEY, Aldous Leonard. Admirável Mundo Novo. Trad. Vidal de Oliveira e Lino Vallandro. 5. ed. Porto Alegre: Globo, 1979.

JONAS, Hans. O princípio responsabilidade: ensaio de uma ética para a civilização tecnológica. Trad. Luiz Barros Montes, Marijane Lisboa. Rio de Janeiro: Contraponto, 2006.

JUNGES, José Roque. A concepção kantiana de dignidade humana. Estudos Jurídicos, v. 40, n. 2, 2007, p. 84-87.

Bioética: hermenêutica e casuística. São Paulo: Loyola, 2006.

KANT, Immanuel. Fundamentação da metafísica dos costumes. Trad. nova com introdução de notas por Guido Antônio de Almeida. São Paulo: Discurso Editorial: Barcarolla, 2009.

A metafísica dos costumes. Trad. Edson Bini. Bauru: Edipro, 2003.

MARTINS-COSTA, Judith (Org.); MÖELLER, Letícia Ludwig (Org.). Bioética e Responsabilidade. Rio de Janeiro: Forense, 2009. 
MENDONÇA, Paulo Roberto S. Estoicismo. In.: BARRETTO, Vicente de Paulo (Coord.) Dicionário de Filosofia do Direito. São Leopoldo/Rio de Janeiro: Unisinos/ Renovar, 2009, 295-297.

MILOVIC, Miroslav. Kant, Emmanuel. In.: BARRETTO, Vicente de Paulo (Coord.). Dicionário de Filosofia do Direito. São Leopoldo/Rio de Janeiro: Unisinos/ Renovar, 2009, p. 498-501.

MORAES, Maria Celina Bodin de. O conceito de dignidade humana: substrato axiológico e conteúdo normativo. In.: SARLET, Ingo Wolfgang (Org.). Constituição, Direitos Fundamentais e Direito Privado. 3. ed. rev. e ampl., Porto Alegre: Livraria do Advogado, 2010, p. 111-157.

NAÇÕES UNIDAS NO BRASIL. Declaração Universal dos Direitos Humanos. Disponível em: <http://www.onu.org.br/onu-no-brasil/onu-no-brasil/> Acesso em: 25 jan. 2016.

PÉREZ LUÑO, Antonio-Henrique. Los derechos humanos en la sociedad tecnológica. Madrid: Universitas, 2012.

PICO DELLA MIRANDOLA, Giovanni. Discurso sobre a dignidade do homem. Ed. bilingue. Lisboa: Edições 70,2006 .

PIOVESAN, Flávia. Direitos Humanos e Direito Constitucional Internacional. 13. ed. rev. e atual. São Paulo: Saraiva, 2012.

ROSEN, Michael. Dignity: its history and meaning. Cambridge: Harvard University Press, 2012.

SARLET, Ingo Wolfgang. A Eficácia dos Direitos Fundamentais. 11. ed., Porto Alegre: Livraria do Advogado, 2012.

Dignidade da Pessoa Humana I e II. In.: BARRETTO, Vicente de Paulo (Coord.). Dicionário de Filosofia do Direito. São Leopoldo/Rio de Janeiro: Unisinos/ Renovar, 2009, p. 212-225.

TEPEDINO, Gustavo. Temas de Direito Civil - Tomo III. Rio de Janeiro: Renovar, 2009.

VITÓRIA, Francisco de. Relaciones del Estado, de los indios y del Derecho de la guerra. México: Porrua, 1974.

Trabalho enviado em 26 de maio de 2016.

Aceito em 31 de agosto de 2016. 